\title{
Bedside voluntary and evoked forces evaluation in intensive care unit patients, not only force evaluation: a letter to the Editor
}

\author{
Paulo Eugênio Silva ${ }^{1 *}\left(\mathbb{0}\right.$, João Luiz Quaglioti Durigan² and Nicolas Babault ${ }^{3}$
}

Dear Editor,

We read with great interest the article by Kennouche et al. [1] related to the evaluation of force in intensive care units (ICU). As indicated in their paper, numerous ICU patients develop a specific disease affecting their future quality of life; the so-called intensive care unitacquired weakness (ICUAW). Early diagnosis associated with early treatment could limit these long-term effects but is challenging. Indeed, while some tools can be used in awake and cooperative individuals, an ICUAW diagnosis in sedated patients is technically difficult. For this reason, in this very well-conducted narrative review, the authors presented protocols that could be used to measure evoked force using electrical or magnetic stimulation in sedated individuals. In addition, tools and reliability data are presented.

Because ICUAW is often related to a reduction in force and muscle atrophy, the authors focused on the assessments of force. Nevertheless, beyond the scope of this review, electrical stimulation also allows the measurement of some neuromuscular electrophysiological disorders and should not be considered only for force evaluation. For example, an evaluation based on stimulus

This comment refers to the article available online at https://doi.org/10.1186/ s13054-021-03567-9.

*Correspondence: pauloeugenio.bsb@gmail.com

${ }^{1}$ Research Group Fisiologia Clínica e Inovação Tecnológica (CNPq); Physical Therapy Division, Hospital de Base do Distrito Federal (IGESDF), Brasília, DF 70330-150, Brazil

Full list of author information is available at the end of the article electrodiagnosis (i.e., motor excitability thresholds, for instance, with chronaxie data or H-reflex-Mwave recruitment curves) could be achieved with standard neuromuscular electrical stimulation [2]. Therefore, we believe this procedure should be used in complement with force evaluation. This is safe and feasible in the ICU and enables the detection of neuromuscular electrophysiological disorders [3].

As previously shown, force significantly decreases during the first days in the ICU. Early treatment with electrical stimulation is efficient to counteract these negative effects as it permits maintenance of force and avoids neuromuscular disorders [4]. However, early rehabilitation in the ICU is often complex for several technical reasons. As chronaxie rapidly increases over days in the ICU, we believe that electrodiagnosis could help prescribe optimized electrical stimulation treatments [4]. However, additional experiments should be conducted to determine the reliability of the different evaluation tools and protocols [1] and determine the best electrical stimulation rehabilitation procedure, characteristics, or modality (e.g., using belts or functional electrical stimulation) [5]. As indicated in this narrative review [1], electrical stimulation is an interesting tool for force evaluation in the ICU. However, electrical stimulation in the ICU should be considered in a more holistic manner as it represents a promising technique for improving patient health both during and after ICU stays.

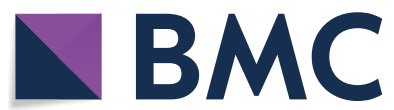

(c) The Author(s) 2021. Open Access This article is licensed under a Creative Commons Attribution 4.0 International License, which permits use, sharing, adaptation, distribution and reproduction in any medium or format, as long as you give appropriate credit to the original author(s) and the source, provide a link to the Creative Commons licence, and indicate if changes were made. The images or other third party material in this article are included in the article's Creative Commons licence, unless indicated otherwise in a credit line to the material. If material is not included in the article's Creative Commons licence and your intended use is not permitted by statutory regulation or exceeds the permitted use, you will need to obtain permission directly from the copyright holder. To view a copy of this licence, visit http://creativecommons.org/licenses/by/4.0/. The Creative Commons Public Domain Dedication waiver (http://creativeco mmons.org/publicdomain/zero/1.0/) applies to the data made available in this article, unless otherwise stated in a credit line to the data. 


\section{ICUAW: Let's focus on force evaluation}

\author{
Djahid Kennouche ${ }^{4 \dagger}$, Eric Luneau ${ }^{4 \dagger}$, Thomas Lapole ${ }^{4}$, \\ Jérome Morel ${ }^{4,5}$, Guillaume Y. Millet ${ }^{4,6+}$ and Julien Gondin ${ }^{7 \dagger}$ \\ ${ }^{\dagger}$ Djahid Kennouche and Eric Luneau equally contributed to this work. \\ ${ }^{\dagger}$ Guillaume Y. Millet and Julien Gondin equally contributed to this work. \\ ${ }^{4}$ Laboratoire Interuniversitaire de Biologie de la Motricité (LIBM), EA 7424, \\ Univ Lyon, UJM-Saint-Etienne, Saint-Etienne, France \\ ${ }^{5}$ Département d'anesthésie et de réanimation, Centre Hospitalier \\ Universitaire, Saint-Etienne, France \\ ${ }^{6}$ Institut Universitaire de France (IUF), Paris, France \\ 7 Institut Neuro-MyoGène (INMG), Université Claude Bernard Lyon 1, CNRS \\ UMR 5310, INSERM U1217, Lyon, France.
}

Djahid Kennouche and Eric Luneau contributed equally to this work.

Guillaume Y. Millet and Julien Gondin contributed equally to this work.

We thank Silva and colleagues for their great emphasis and interest on our recent paper aiming at reviewing the different tools and methods allowing bedside force evaluation in ICU patients [1].

Although we appreciate the suggestion to add electrophysiological measurements in ICU patients, we believe this topic was beyond the scope of our review focusing on the impairment of muscle force during and after an ICU stay. We agree with Silva et al. that it can be an asset, as mentioned in the 'Perspectives' section: "Evoked force measurements should also be combined with surface electromyography and ultrasound analyses [...] to get a clear picture of the deleterious consequences of an ICU stay on the neuromuscular system...". Yet it should be kept in mind that (i) the use of chronaxie for ICUAW diagnosis has never been clinically validated; (ii) $\mathrm{H}$-reflexes are usually absent in patients with critical illness polyneuropathy [6]; (iii) altered muscle membrane excitability [7] may prevent $\mathrm{M}$-wave recordings (Kennouche et al., unpublished observations).

We also clearly highlighted the relevance of beside evoked force measurements for ICUAW treatment. So far, the application of neuromuscular electrical stimulation (NMES), a potential strategy for limiting muscle weakness and/or atrophy in ICU patients, is empirical and relies on a subjective quantification of muscle contraction intensity (i.e., inspection of visible/palpable contractions) [8] as done for the chronaxie assessment. Bedside ergometers would therefore offer the unique opportunity to accurately quantify isometric contractile responses to NMES in ICU patients and could be used to provide evidence-based recommendations in future critical care NMES interventions.

Considering the difficulty in evoking contractile responses in all stimulated muscles and all patients [8], the possibility to produce coordinated movements by functional electrical stimulation (FES)-assisted cycling appears hypothetical in sedated patients. The effects of FES application on muscle strength of mechanically ventilated patients are also still equivocal [9].

As for NMES application, mechanical force/power output produced during FES cycling (e.g., using instrumented pedals) should be monitored to determine the effectiveness of FES on muscle force and mass of ICU patients. To conclude, bedside force measurements should remain at the heart of both diagnosis and treatment of ICUAW.

\section{Acknowledgements \\ None.}

\section{Authors' contributions}

PES and NB developed the letter concept and wrote the manuscript. JLQD revised the manuscript. All authors read and approved the final manuscript.

Funding

There was no funding source for this manuscript.

Availability of data and materials

Not applicable.

\section{Declarations}

Ethical approval and consent to participate Not applicable.

Consent for publication

Not Applicable.

\section{Competing interests}

The authors declare that they have no competing interest.

\section{Author details}

${ }^{1}$ Research Group Fisiologia Clínica e Inovação Tecnológica (CNPq); Physical Therapy Division, Hospital de Base do Distrito Federal (IGESDF), Brasília, DF 70330-150, Brazil. ${ }^{2}$ Graduate Program in Rehabilitation Sciences, Universidade de Brasília, Brasília, DF 70910-900, Brazil. 'INSERM UMR1093 - CAPS, Faculty of Sport Sciences, University of Bourgogne Franche-Comté, 21000 Dijon, France. ${ }^{4}$ Laboratoire Interuniversitaire de Biologie de la Motricité (LIBM), EA 7424, Univ Lyon, UJM-Saint-Etienne, Saint-Etienne, France. ${ }^{5}$ Département d'anesthésie et de réanimation, Centre Hospitalier Universitaire, Saint-Etienne, France. ${ }^{6}$ Institut Universitaire de France (IUF), Paris, France. ${ }^{7}$ Institut NeuroMyoGène (INMG), Université Claude Bernard Lyon 1, CNRS UMR 5310, INSERM U1217, Lyon, France.

Received: 23 May 2021 Accepted: 8 June 2021

Published online: 01 July 2021

\section{References}

1. Kennouche D, Luneau E, Lapole T, Morel J, Millet GY, Gondin J. Bedside voluntary and evoked forces evaluation in intensive care unit patients: a narrative review. Crit Care. 2021;25:157.

2. Lacomis D. Electrophysiology of neuromuscular disorders in critical illness. Muscle Nerve. 2013;47:452-63.

3. Silva PE, Babault N, Mazullo JB, Oliveira TP, Lemos BL, Carvalho VO, et al. Safety and feasibility of a neuromuscular electrical stimulation chronaxiebased protocol in critical ill patients: a prospective observational study. J Crit Care. 2017;37:141-8. 
4. Silva PE, De Cássia Marqueti R, Livino-De-Carvalho K, De Araujo AET, Castro J, Da Silva VM, et al. Neuromuscular electrical stimulation in critically ill traumatic brain injury patients attenuates muscle atrophy, neurophysiological disorders, and weakness: A randomized controlled trial. J Intensive Care. 2019;7:59.

5. Al-Shekhlee A, Hachwi RN, Preston DC. Early rehabilitation in ICU for COVID-19: what about FES-cycling? Crit Care. 2021;25:94

6. Al-Shekhlee A, Hachwi RN, Preston DC, Katirji B. New criteria for early electrodiagnosis of acute inflammatory demyelinating polyneuropathy. Muscle Nerve. 2005;32:66-72.

7. Weber-Carstens S, Koch S, Spuler S, Spies CD, Bubser F, Wernecke KD, et al. Nonexcitable muscle membrane predicts intensive care unit-acquired paresis in mechanically ventilated, sedated patients. Crit Care Med. 2009;37:2632-7.
8. Grunow JJ, Goll M, Carbon NM, Liebl ME, Weber-Carstens S, Wollersheim T. Differential contractile response of critically ill patients to neuromuscular electrical stimulation. Crit Care. 2019;23:308.

9. Berney S, Hopkins RO, Rose JW, Koopman R, Puthucheary Z, Pastva $A$, et al. Functional electrical stimulation in-bed cycle ergometry in mechanically ventilated patients: a multicentre randomised controlled trial. Thorax. 2020. https://doi.org/10.1136/thoraxjnl-2020-215093.

\section{Publisher's Note}

Springer Nature remains neutral with regard to jurisdictional claims in published maps and institutional affiliations.
Ready to submit your research? Choose BMC and benefit from:

- fast, convenient online submission

- thorough peer review by experienced researchers in your field

- rapid publication on acceptance

- support for research data, including large and complex data types

- gold Open Access which fosters wider collaboration and increased citations

- maximum visibility for your research: over $100 \mathrm{M}$ website views per year

At BMC, research is always in progress.

Learn more biomedcentral.com/submissions 